Advances in Geosciences (2005) 2: 1-6

SRef-ID: 1680-7359/adgeo/2005-2-1

European Geosciences Union

(c) 2005 Author(s). This work is licensed

under a Creative Commons License.

\title{
Dynamics of intense convective rain cells
}

\author{
A. Parodi \\ CIMA, University of Genoa and University of Basilicata, Italy
}

Received: 19 November 2004 - Revised: 24 January 2005 - Accepted: 25 January 2005 - Published: 11 February 2005

\begin{abstract}
Intense precipitation events are often convective in nature. A deeper understanding of the properties and the dynamics of convective rain cells is, therefore, necessary both from a physical and operational point of view. The aim of this work is to study the spatial-temporal properties of convective rain cells by using a fully parameterized nonhydrostatic code (Lokal Model) in simplified model configurations. High resolution simulations are performed and it is expected that the deep moist convection and the feedback mechanisms affecting larger scales of motion can then be resolved explicitly and some of the critical constraints of parameterization schemes can be relaxed. The sensitivity of the spatio-temporal properties of simulated cells to spatial resolution and microphysics schemes is investigated and discussed through a direct comparison with typical intense convective cells measured by radars.
\end{abstract}

\section{Introduction}

Intense convective rain cells are often responsible for extreme hydrometeorological events with serious and relevant consequences from a social and economic standpoint. Therefore, the analysis of the spatio-temporal properties of these structures is relevant both theoretically and operationally. Traditionally, this topic has been addressed in literature along two main lines:

i) A direct analysis of convective fields observed by remote sensors, such as radar and satellite, in order to provide an interpretation of small scale properties which characterize these cells depending on their evolution, geographical localization and environmental forcings (Austin and Houze, 1972; Zavadski, 1973; Austin and Locatelli, 1978; Houze and Hobbs, 1982; Szoke et al., 1986; Cotton and Anthes, 1989; Feral et al., 2000; von Hardenberg et al., 2003);

Correspondence to: A. Parodi

(antonio@cima.unige.it) ii) The use of high resolution atmospheric numerical models which allow the simulation of different convective cell scenarios (Klemp and Wilhelmson, 1978; Weisman and Klemp, 1982, 1984). In this way it is possible to study in detail the different forms in which deep moist convection develops: from isolated cumulonimbus cells, through squall lines, to mesoscale convective complexes.

In this work the second approach is followed, using the Lokal model (Doms and Schaettler, 1999) as a numerical framework, so as to gain a deeper understanding of basic processes of intense convective precipitation in simplified configurations (convection over flat surface, simple wind shear, etc.) with high resolution (meso- $\gamma$ and micro- $\alpha$ scales) simulations. Therefore the convection dynamics can be resolved explicitly avoiding the use of sometimes questionable parameterization schemes. Besides, the sensitivity of results to computational and physical details can be evaluated in great detail. This aspect has recently deserved a growing attention and some works have proved that numerical models show sensitivity to their numerical and physical formulation, numerical parameters and boundary conditions (Adlerman and Drogemeier, 2002; Bryan et al., 2003).

\section{Numerical model}

The numerical simulations discussed in this work have been performed using the Lokal Model, which is a nonhydrostatic limited area model. The Lokal Model, created in 1998 by the DWD (Germany) and developed ever since, is used for operational purposes, in the context of the COSMO consortium, by several national and regional meteorological services in Europe. This section gives only a short overview of the Lokal Model, for a comprehensive description the reader is referred to Steppeler et al. (2003). This model is formulated using the primitive hydro-thermodynamical equations describing compressible nonhydrostatic flow in a moist atmosphere without any scale approximations. The prognostic model variables are the wind vector, temperature, pressure perturbation, 


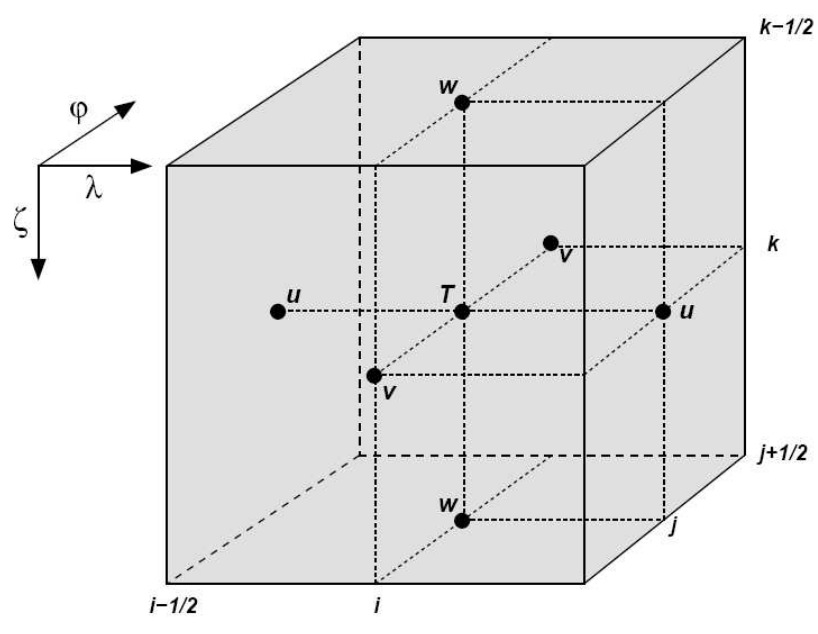

Fig. 1. Lokal Model computational grid: Arakawa C/Lorenz grid.

specific humidity, cloud liquid water, rain and snow sedimentation fluxes. The basic state describes a dry atmosphere at rest which is defined as horizontally homogeneous, vertically stratified and in hydrostatic balance. The basic equations are written in advection form and the continuity equation is replaced by the prognostic equation of the perturbation pressure. The Lokal Model adopts a generalized terrainfollowing coordinate $\zeta$ and an Arakawa C/Lorenz grid with scalars (temperature, pressure and moist variables) defined at the center of a grid box and the normal velocity components defined on the corresponding box sides (Fig. 1).

The model adopts a second order horizontal and vertical differenciating approach. Different time integration schemes are offered to the user: a leapfrog HE-VI (horizontally explicit and vertically implicit) time split integration scheme, a two time-level split-explicit scheme (Gassmann, 1992), a three time level 3D semi-implicit scheme (Read et al., 2000) and a two time level 3rd-order Runge-Kutta scheme with various options for high-order spatial discretization (Doms and Forstner, 2004). The physics of the model is based on different parameterization packages, e.g. a level 2.5 moist turbulence parameterization, a $\delta$-two stream radiation scheme (Ritter and Geleyn, 1992) and a two layer soil model (Jacobson and Heise, 1982). The model includes a grid-scale cloud and precipitation scheme as well as different parameterizations of moist convection (Tiedtke, 1989; Kain and Fritsch, 1993) . The Lokal Model offers several microphysical schemes spanning from the classical warm rain scheme (Kessler, 1969) to a graupel scheme.

\section{Numerical experiments}

The study of the basic processes of intense convective precipitation is addressed by performing high resolution simulations of deep moist convective structures over a flat surface at the interface between the meso- $\gamma$ and the micro- $\alpha$ scales. In this way the convection dynamics can be modelled explic-

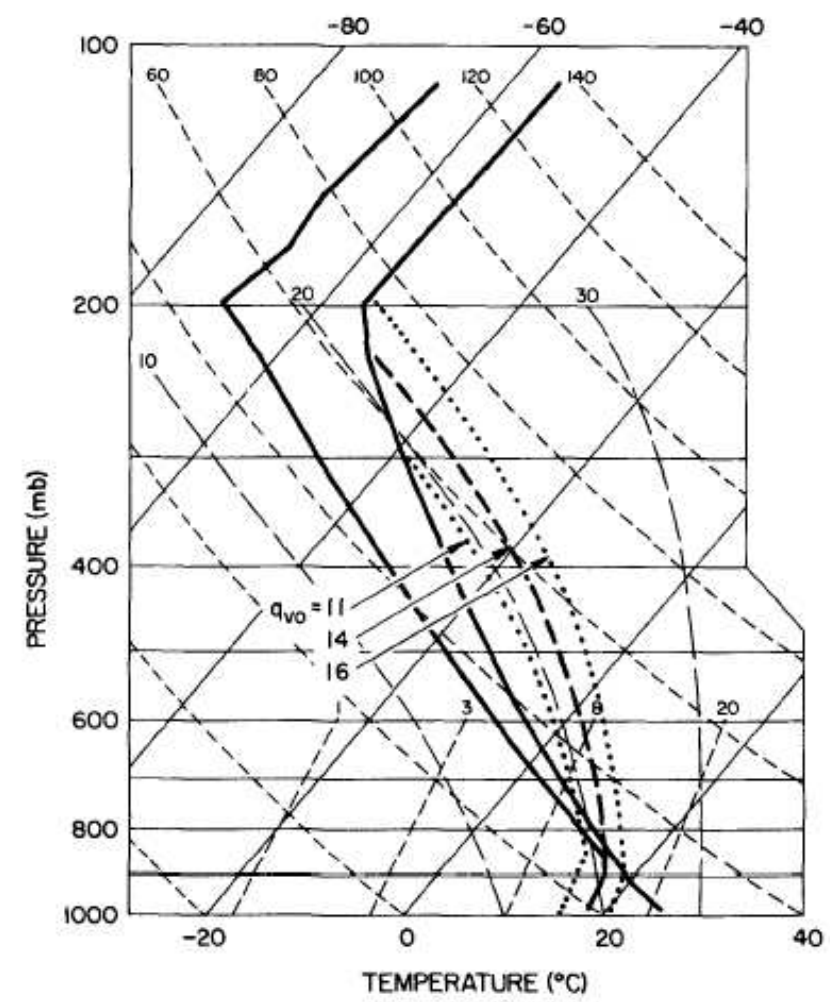

Fig. 2. Skew T diagram showing the temperature and moisture profiles used in the simulations. In this work a surface mixing ratio $q_{v 0}=14 \mathrm{~g} / \mathrm{kg}$ is assumed. Tilted solid lines represent isotherms, long dashed lines are moist adiabats while short dashed lines are dry adiabats (picture from Weisman and Klemp, 1982).

itly and it might be possible to benefit from a more detailed representation of cloud-microphysics and transport of convective cells with the wind field (impact of shear).

The numerical simulations are initialized considering a horizontally homogeneous atmosphere in which an axially symmetric thermal perturbation (warm bubble) of vertical radius $1400 \mathrm{~m}$ and horizontal radius $10 \mathrm{~km}$ (Weisman and Klemp, 1982, 1984) is placed. The amplitude of the temperature perturbation is maximum in the cell center $\left(2^{\circ} \mathrm{C}\right)$ and gradually decreases approaching the bubble boundaries. This warm bubble acts as a triggering mechanism for deep convection dynamics (initial value type problem). The computational domain size is $300 \times 300 \times 18 \mathrm{~km}$ with horizontal grid spacing spanning from $2 \mathrm{~km}$ to $1 \mathrm{~km}$ : finer resolution simulations (500 and $250 \mathrm{~m}$ ) will be carried out at a later stage. The vertical grid spacing stretches gradually from $80 \mathrm{~m}$ near the bottom boundary to $500 \mathrm{~m}$ near the top one.

The vertical profiles of potential temperature and moisture inside the computational domain are defined according to Weisman and Klemp $(1982,1984)$. The environmental potential temperature profile is given by:

$\bar{\theta}(z)=\theta_{0}+\left(\theta_{t r}-\theta_{0}\right)\left(\frac{z}{z_{t r}}\right)^{\frac{5}{4}}, \quad z \leq z_{t r}$

$\bar{\theta}(z)=\theta_{t r} \exp \left[\frac{g}{c_{p} T_{t r}}\left(z-z_{t r}\right)\right], \quad z>z_{t r}$ 
The environmental relative humidity profile is given by:

$\bar{H}(z)=1-\frac{3}{4}\left(\frac{z}{z_{t r}}\right)^{\frac{5}{4}}, \quad z \leq z_{t r}$

$\bar{H}(z)=0.25, \quad z>z_{t r}$

where $z_{t r}=12000 \mathrm{~m}, \quad \theta_{t r}=343 \mathrm{~K}, \quad T_{t r}=213 \mathrm{~K}$ and $\theta_{0}=300 \mathrm{~K}$. A surface value of water vapour mixing ratio $q_{v 0}=14 \mathrm{~g} / \mathrm{kg}$ is chosen. The potential temperature and moisture profiles are shown in Fig. 2.

The experiments are run adopting Davies relaxation boundary conditions, leapfrog HE-VI time integration scheme, a 4th order linear horizontal diffusion coefficient and Rayleigh damping layers in the upper layers $(z \geq 12 \mathrm{~km})$.

The radiation parameterization is not taken into account since the radiative processes are effective on time scales much higher than those typical of the short-lived, intense deep convective cells considered in this work. The vertical diffusion processes are modelled through a 2.5 scheme with prognostic treatment of turbulent kinetic energy which allows the effects of subgrid-scale condensation, evaporation and thermal circulations on cell dynamics to be taken into account. Finally a warm rain microphysical scheme (Kessler, 1969) is adopted.

Two numerical experiments will be discussed in the following two sections. The first experiment will address the study of vertical wind shear effect on deep convection dynamics. The second one, instead, will consider the case of a single convective cell developing in the absence of wind. The sensitivity of spatio-temporal properties of intense deep convective cells to computational parameters such as horizontal grid spacing and numerical diffusion will be investigated. Furthermore some preliminary comparisons between simulated and radar observed cells will be described.

\subsection{Numerical experiment 1}

In this experiment the warm bubble center is placed at the point $(52,80) \mathrm{km}$ near the lower left corner of the domain. The wind shear profile has been chosen to highlight as much as possible the role of vertical wind shear on deep storm dynamics (Fig. 3): the shear vector rotates $180^{\circ}$ over the lowest $5 \mathrm{~km}$ of the atmosphere, while the wind becomes constant and one-directional above $5 \mathrm{~km}$.

Firstly, by assuming a reference value of horizontal grid spacing $\Delta x=\Delta y=1 \mathrm{~km}$ and an integration time step $\Delta t=1 \mathrm{~s}$, the effect of different values of 4 th order numerical horizontal diffusion coefficient of storm dynamics has been studied. The horizontal numerical diffusion operator reduces the effect of spurious oscillations on numerical results. As it should be most effective on waves with a wavelength of two grid intervals, solutions adopting different values of such artificial viscosity should be qualitatively similar when the specified diffusion coefficient is sufficiently small. In particular, since for a generic field $\psi$ the horizontal diffusion operator is given by:

$M_{\psi}^{C M}=K_{4}^{h} \nabla^{2}\left(\nabla^{2} \psi\right)$

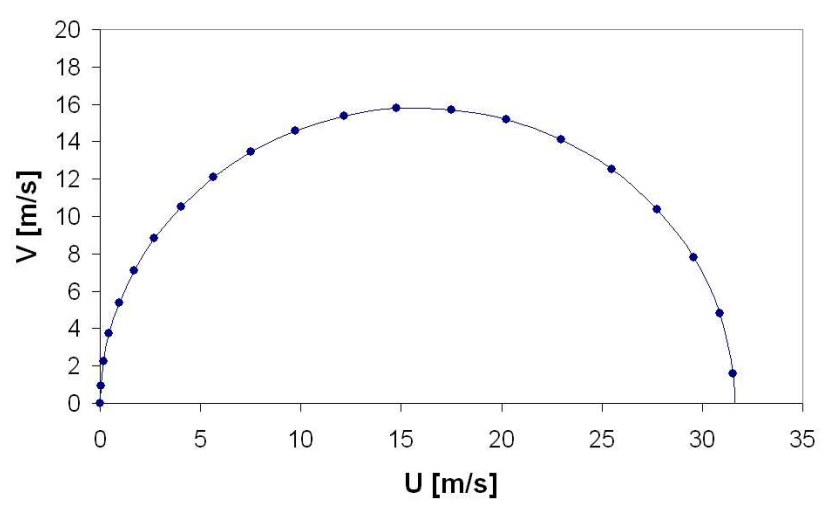

Fig. 3. Wind hodograph used in the numerical experiment 1. Winds become constant and one-directional above $5 \mathrm{~km}$.

Table 1. Three different values of scaling coefficient $c$ for horizontal diffusion coefficient.

\begin{tabular}{cl}
\hline Run & $c$ \\
\hline 1 & 0.1 \\
2 & 0.5 \\
3 & 1.0 \\
\hline
\end{tabular}

a maximum value of the horizontal diffusion coefficient is defined through linear stability considerations

$K_{4, \max }^{h}=\frac{(\Delta x)^{4}}{128 \Delta t}$

and the model results are compared according to three different values of $K_{4}^{h}=c K_{4, \text { max }}^{h}$, where $\mathrm{c}$ is the scaling coefficient (Table 1).

From a qualitative point of view these three runs generate similar scenarios: the initial cell evolves into a cyclonic, right-moving supercell. The low-level vertical wind shear and cold pool circulation, in combination with the propagation of internal gravity waves, promote deep lifting along the downshear portion of the gust front, with new ordinary cells generated to the north of the supercell. From an dynamical viewpoint these new cells are weaker and less persistent than the supercell.

The effects of different values of the horizontal diffusion coefficient on some quantitative aspects of deep convection dynamics are analyzed through the temporal evolution of the maximum value of vertical velocity in each run. The behaviors are quite different especially during the first hour of simulation: run 1 has a faster evolution in respect to the more diffusive ones, but it seems also more unstable (Fig. 4). Similar considerations are valid for the temporal evolution of the maximum value of the horizontal wind (Fig. 5). The variation of numerical diffusion does not affect only such simple statistics, but also the vertical and horizontal organization of the flow field. In Fig. 6, for run 1 and 2, two horizontal cross sections of the vertical velocity field, at elevation $z=1000 \mathrm{~m}$ 


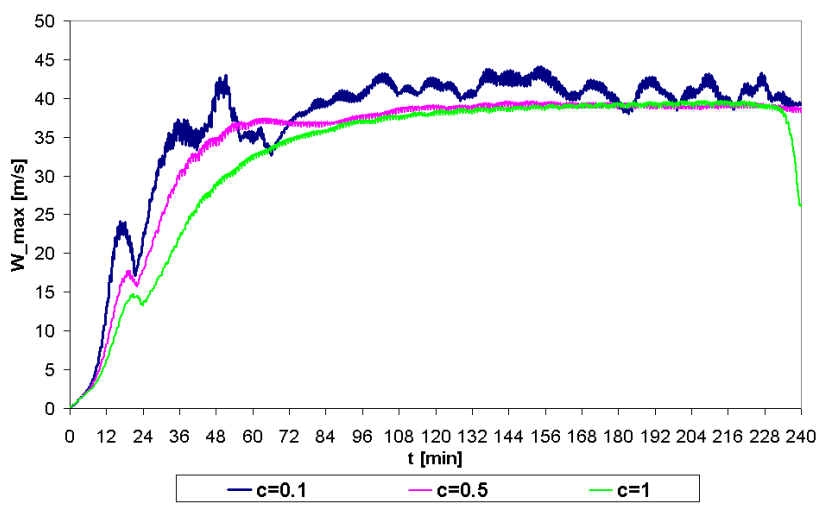

Fig. 4. Temporal evolution of maximum vertical wind for different horizontal diffusion coefficients.

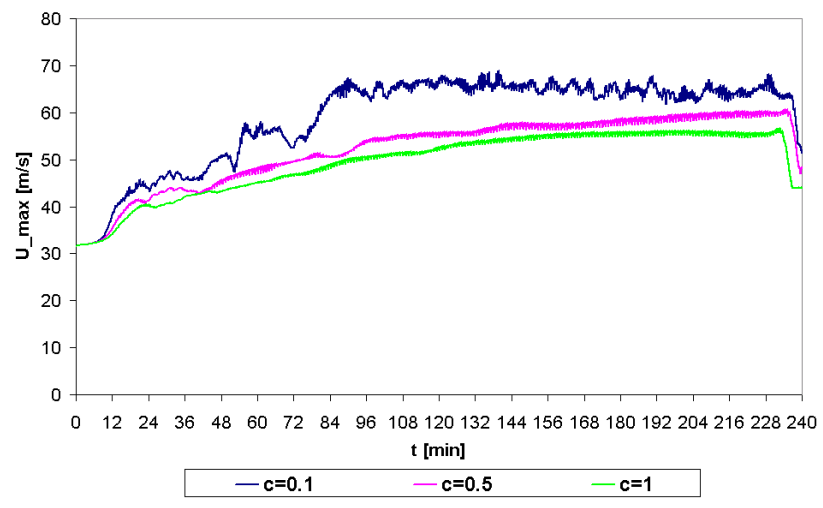

Fig. 5. Temporal evolution of maximum horizontal wind for different horizontal diffusion coefficients.

and timestep $t=180$ minutes are compared. The flow fields look quite different especially in the upper part of the domain, where the secondary cells are different in number and localization. The reasons for such behavior are not clear at the moment and further analysis will be necessary to single out clearly the dominant mechanism responsible for the development of these secondary cells.

The effect of varying horizontal grid spacing on model results has also been evaluated. In particular, a run, with horizontal resolution $\Delta x=\Delta y=2 \mathrm{~km}$ and an integration time step $\Delta t=2 \mathrm{~s}$, characterized by the same value of $K_{4}^{h}$ assumed for run 2 has been performed. The variation in grid spacing seems to alter seriously the flow field pattern (Fig. 7): the coarser simulation does not show at all the development of secondary cells to the north of the supercell. Also the vertical structure of the supercell is strongly modified: the coarser simulation produces a shorter and larger supercell (Fig. 8).

\subsection{Numerical experiment 2}

The results of experiment 1 suggest further simplification of the study case is needed. Therefore, the second experiment is about the modelling of the simplest deep convective scenario: the case of a single cell which develops in the absence
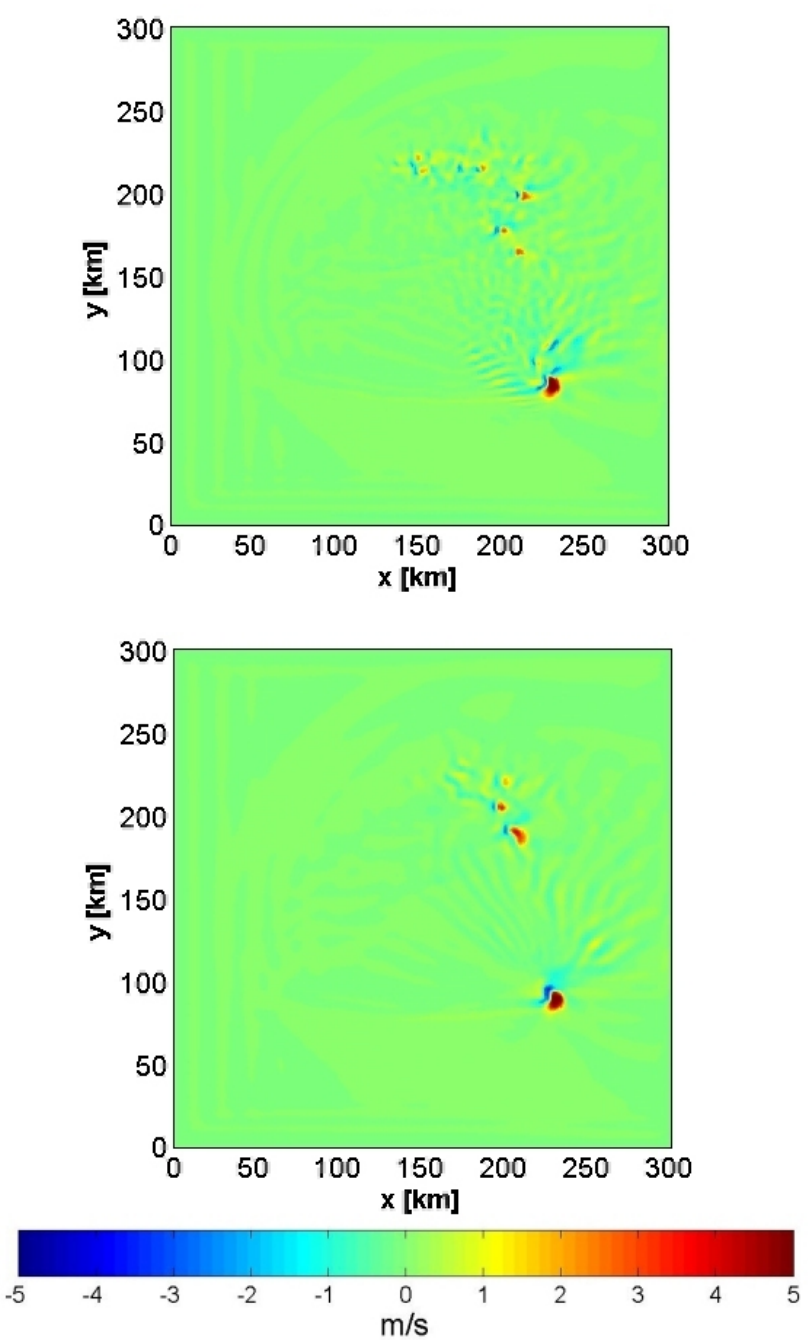

Fig. 6. Horizontal cross sections $(z=1000 \mathrm{~m}$ and $t=180 \mathrm{~min}$ of the vertical velocities field for run 1 (upper panel) and run 2 (lower panel).

of wind shear. A warm bubble is put in the center of the domain so as to trigger the development of a single convective cell. By assuming the same value of $K_{4}^{h}$ valid for run 2 (experiment 1$)$, the effect of horizontal grid spacing ( $1 \mathrm{~km}$ and $2 \mathrm{~km}$ ) variation on cell evolution has been studied . Qualitatively these two runs produce similar results: the initial cell grows and decays over the first hour with new weak cells generated as the surface cold pool first begins to spread out. These new cells, responsible for the kinks in the two profiles in Fig. 9, dissipate quickly as the cold pool continues to propagate away, with the cold pool circulation unable to produce sufficient lifting for sustaining effective cell regeneration. However, the temporal evolution of the maximum value of vertical velocity is quite different (Fig. 9).

When the simulation is coarser, the cell is less intense, but surprisingly it presents a slower decay.

As mentioned before, part of the work is devoted to the direct comparison between spatio-temporal properties of 

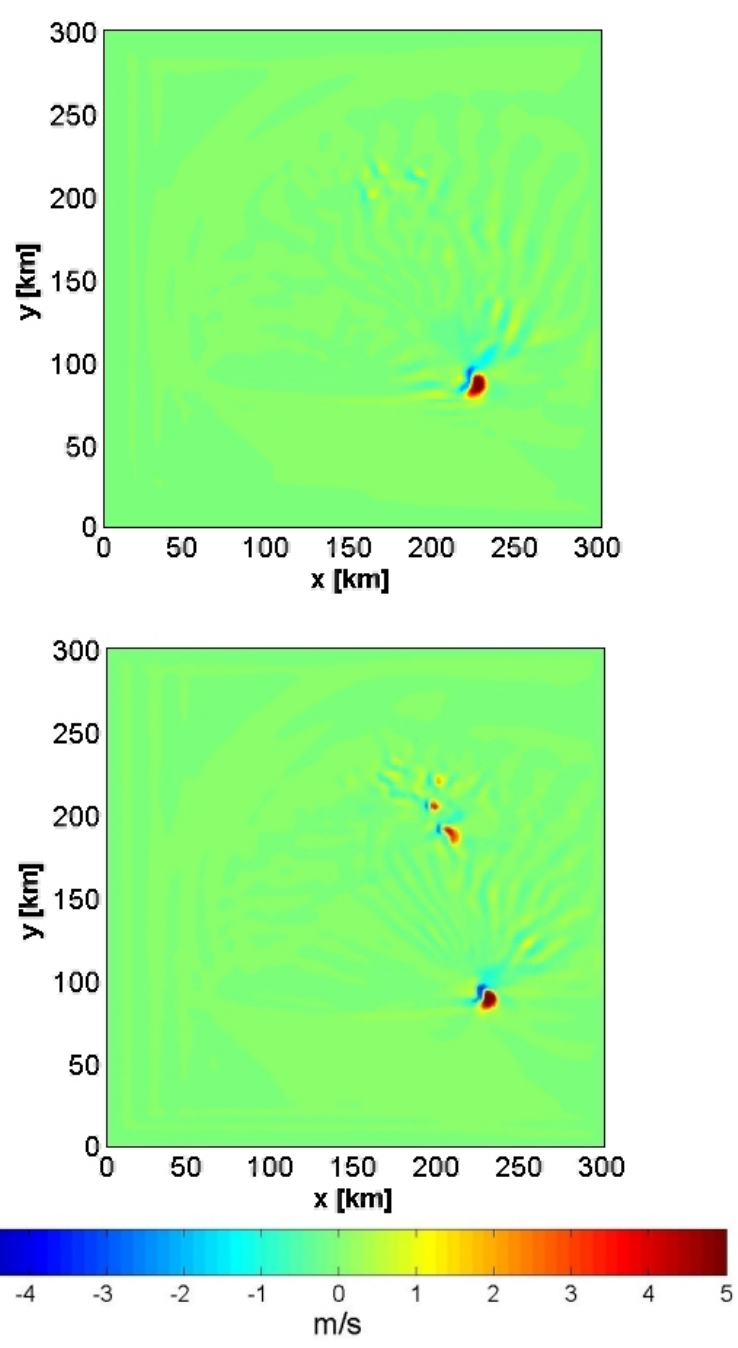

Fig. 7. Horizontal cross sections $(z=1000 \mathrm{~m}$ and $t=180 \mathrm{~min})$ of the vertical velocities field for $2 \mathrm{~km}$ run (upper panel) and $1 \mathrm{~km}$ run (lower panel).

simulated cells and radar measured cells. In fact von Hardenberg et al. (2003) have recently shown that convective rain cells over the ocean are exponential in shape. They define shape as the spatial distribution of rainfall intensity around the cell center. These findings are also confirmed by the preliminary analysis of the shape of the single rain cell considered in this experiment (Fig. 10).

It must be stressed that these results are really at an initial stage. A physical understanding of this behavior which assesses, for example, its sensitivity to microphysical scheme details, needs further investigation. Besides, the dependence of the shape of rain cells on the three-dimensional spatial structure of microphysical fields will have to be analyzed.

\section{Conclusions}

The dynamics of deep convective cells in simplified model configurations has been investigated by using the Lokal
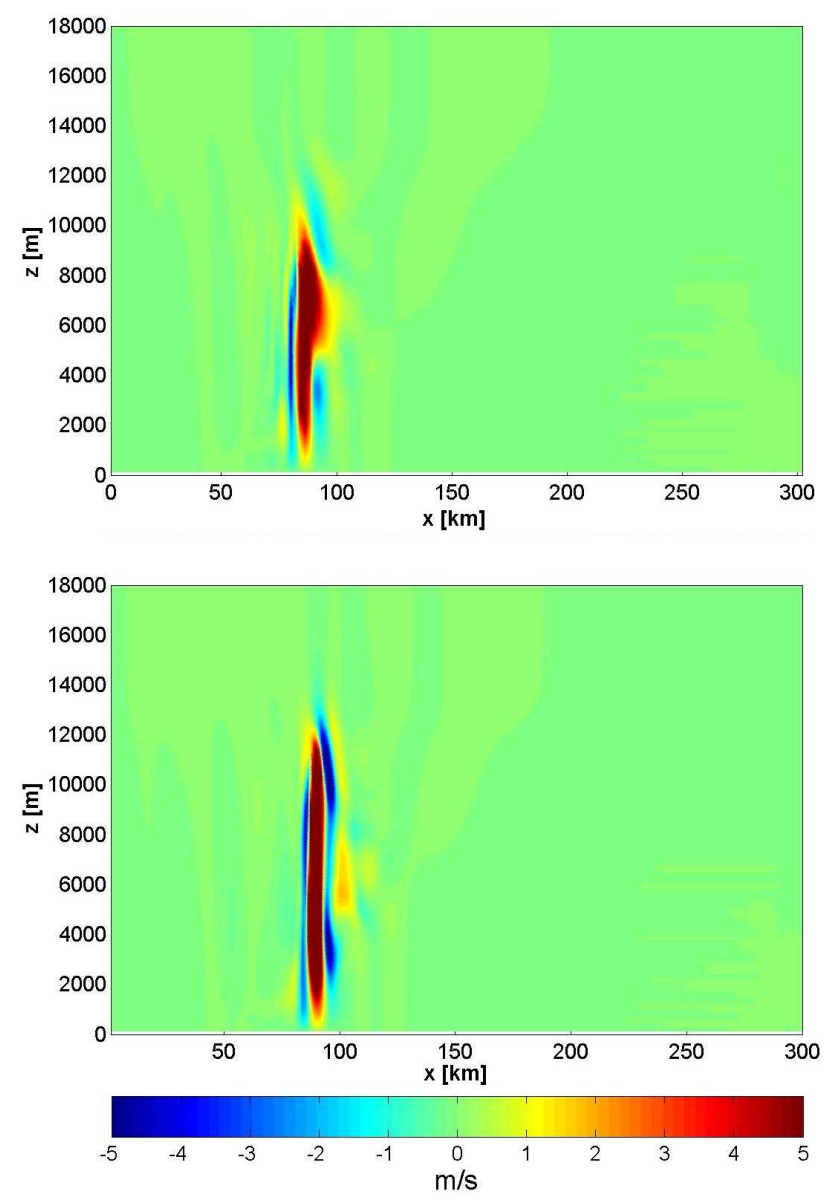

Fig. 8. Vertical cross sections ( $y=100 \mathrm{~km}$ and $t=42 \mathrm{~min}$ ) of the vertical velocities field for $2 \mathrm{~km}$ run (upper panel) and $1 \mathrm{~km}$ run (lower panel).

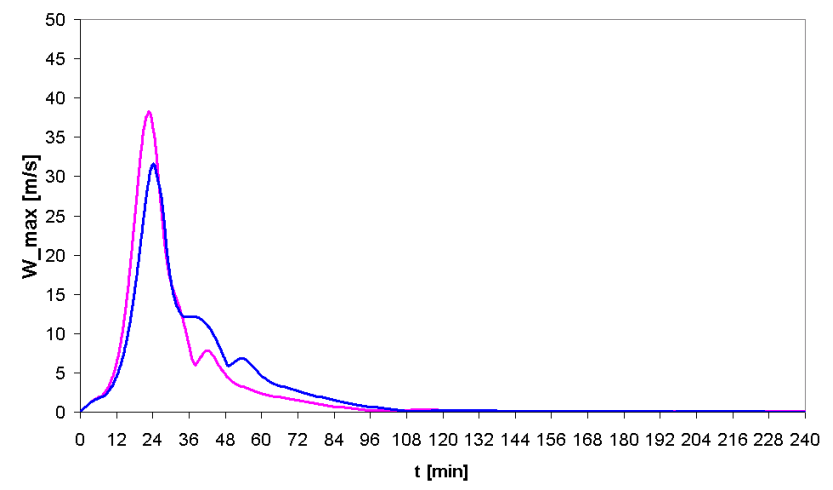

Fig. 9. Temporal evolution of maximum vertical velocity for different horizontal grid spacing ( $1 \mathrm{~km}$ pink, $2 \mathrm{~km}$ blue).

Model as a numerical framework in order to obtain a deeper understanding of basic processes of intense convective precipitation. The preliminary results, presented here, are promising and call for further analysis. In particular, the spatio-temporal properties of convective cells are found to be quite dependent on numerical and physical parameters such 


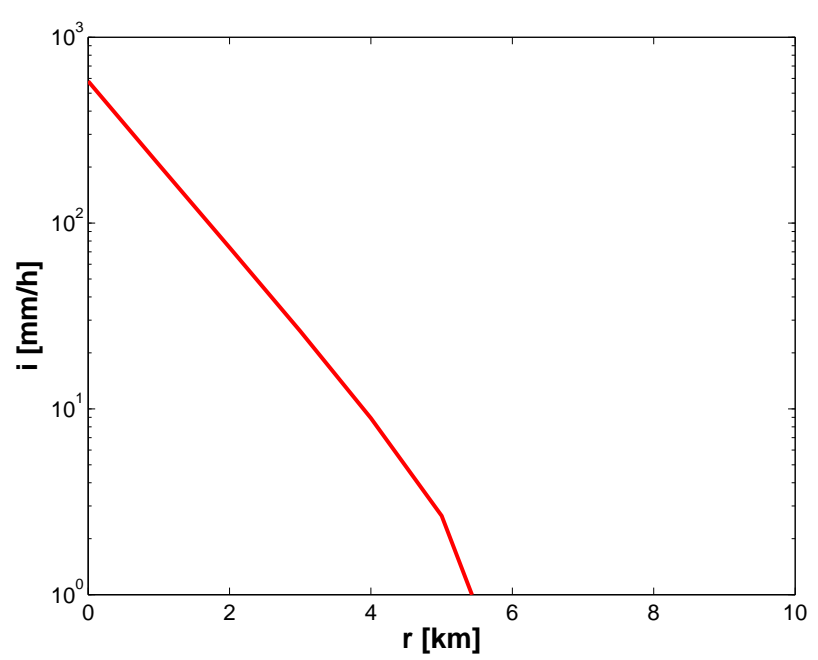

Fig. 10. Log-linear plot of the instantaneous profile $(t=39 \mathrm{~min})$ of the rainfall intensity for single cell simulation: $r$ represents the distance from the cell center.

as numerical diffusion and horizontal grid spacing (Adlerman and Drogemeier, 2002). The work is in progress. A physical explanation of such behaviors will be carried out, also through a comparison between the characteristics of simulated convective cells and cells measured by radars. The role of other parameters (microphysical scheme, surface drag coefficient) on model performances, even at lower horizontal resolution $(500-250 \mathrm{~m})$, will also be evaluated. In particular The effects of these results in the understanding of deep convection dynamics as well as in the context of LAM numerical weather prediction will be considered.

Acknowledgements. The author is grateful to G. Doms for his invaluable contribution, without which this work would not have been possible. Gratitude is also extended to A. Provenzale, J. v. Hardenberg, F. Siccardi, L. Ferraris and T. Paccagnella for their enlighting discussions and useful comments.

Edited by: L. Ferraris

Reviewed by: anonymous referees

\section{References}

Adlerman, E. and Drogemeier, K.: The sensitivity of numerically simulated cyclic mesocyclogenesis to variations in model physical and computational parameters, Mon. Wea. Rev., 130, 26712691, 2002.

Austin, P. M. and Houze, R. A.: Analysis of the structure of precipitation patterns in New England, J. Appl. Meteorol., 11, 926-935, 1972.

Austin, P. V. J. and Locatelli, J. D.: Rainbands, precipitation cores and generating cells in a cyclonic storm, J. Atmos. Sci., 35, 230$241,1978$.
Bryan, G. H., Wyngaard, J. C., and Fritsch, J. M.: Resolution requirements for the simulation of deep moist convection, Mon. Wea. Rev., 131, 2394-2416, 2003.

Cotton, W. R. and Anthes, R.: Storm and cloud dynamics, Academic Press, 1989.

Doms, G. and Forstner, J.: Development of a kilometer-scale NWPsystem: LMK, COSMO Newsletter, 4, 159-167, 2004.

Doms, G. and Schaettler, U.: The nonhydrostatic limited-area model LM (Lokal-Modell) of DWD. Part I: Scientific documentation, Deutscher Wetterdienst (DWD), 1999.

Feral, L., Fedi, F., Magistroni, C., Paraboni, A., and Pawlina, A.: Rain cells shape and orientation distribution in Southern West France, Phys. Chem. Earth B, 25, 1073-1078, 2000.

Gassmann, A.: A two timelevel Integration Scheme for the LM, COSMO Newsletter, 2, 1992.

Houze, R. A. J. and Hobbs, P. V.: Organization and structure of precipitating cloud systems, Adv. Geophys., 24, 225-315, 1982.

Jacobson, I. and Heise, E.: A new economic method for the computation of the surface temperature in numerical models, Beitr. Phys. Atm., 55, 128-141, 1982.

Kain, J. S. and Fritsch, J. M.: Convective parameterization for mesoscale models: The Kain-Fritsch scheme, Meteorological Monographs, 46, 165-170, 1993.

Kessler, E.: On the distribution and continuity of water substanceon atmospheric circulation, Meteorol. Monogr., 10 (32), 1969.

Klemp, J. and Wilhelmson, R.: The simulation of three-dimensional convective storm dynamics, J. Atmos. Sci., 35, 1070-1096, 1978.

Read, P. L., Thomas, N. P. J., and Risch, S. H.: An Evaluation of Eulerian and Semi-Lagrangian Advection Schemes in Simulations of Rotating, Stratified Flows in the Laboratory. Part I: Axisymmetric Flow, Mon. Wea. Rev., 128, 2835-2852, 2000.

Ritter, B. and Geleyn, J. F.: A comprehensive radiation scheme for numerical weather prediction models with potential applications in climate simulations, Mon. Wea. Rev., 120, 303-325, 1992.

Steppeler, J., Hess, R., Doms, G., Schättler, U., and Bonaventura, L.: Review of numerical methods for nonhydrostatic weather prediction models, Meteorology and Atmospheric Physics, Meteor. Atmos. Phys., 82, 287-301, 2003.

Szoke, E., Zipser, E., and Jorgensen, D.: A radar study of convective cells in GATE. Part I: Vertical profile statistics and comparison with hurricane cells., J. Atmos. Sci., 43, 184197, 1986.

Tiedtke, M.: A comprehensive mass flux scheme for cumulus parameterization in large scale models., Mon. Wea. Rev., 117, 1779-1800, 1989.

von Hardenberg, J., Provenzale, A., and Ferraris, L.: The shape of rain cells, Geophys. Res. Lett., 30, doi:10.1029/2003GL018 539, 2003.

Weisman, M. L. and Klemp, J.: The dependence of of numerically simulated convective storms on vertical wind shear and buoyancy, Mon. Wea. Rev., 110, 504-520, 1982.

Weisman, M. L. and Klemp, J.: The structure and classification of numerically simulated convective storms in directionally varying wind shears, Mon. Wea. Rev., 112, 2479-2498, 1984.

Zavadski, I. I.: Statistical properties of precipitation events, J. Appl. Meteorol., 12, 459-472, 1973. 